\title{
Ideal Careers Perceived by Education Major Undergraduates in Taiwan
}

\author{
Hsuan-Fu Ho ${ }^{1}$ \\ ${ }^{1}$ National Chiayi University, Taiwan \\ Correspondence: Hsuan-Fu Ho, National Chiayi University, Taiwan. E-mail: hfho@mail.ncyu.edu.tw
}

Received: December 5, 2012

Accepted: December 24, 2012 Online Published: March 4, 2013

doi:10.5539/ies.v6n4p39

URL: http://dx.doi.org/10.5539/ies.v6n4p39

\begin{abstract}
The higher educational institutions produce several times as many college graduates each year as there are jobs available recently in Taiwan. This coupled with the deep recession of economy in recent years have contributed to the intensified competition for jobs. The fierce unemployment among young people has revived the demand on the contribution of educational system to the employability of college graduates. Since exploring how students define an ideal job is a prerequisite for guiding them get a job that better matches their skills and desires, this research is thus endeavored to identify the major determinants of career selection, to calculate the relative importance of each determinant, and to decide the major strengths of different careers. AHP was adopted as the major tool for calculating the relative importance of the determinants of career selection, Correspondence Analysis was used to create perceptual map for identifying major strengths of different careers. The results showed that Career Security and Retirement Policy were the most important determinants of job selection; moreover, students major in education preferred careers in public sectors such as public school teacher and government official.
\end{abstract}

Keywords: career, job choice, higher education, AHP, correspondence analysis

\section{Background}

For the past decades, many countries have been giving increasing emphasis on expanding their higher educational system, in the belief that the expansion will contribute to equal education opportunity and economic growth, and will meet the increasing demand for knowledge and skills that associated with the advent of knowledge-based economy (Teichler, 1999; Yorke and Knight, 2006; Barone and Ortiz, 2010). Taiwan is no exception, the number of higher educational institutions have been dramatically expanded from 28 to 164 in 30 years since 1986 (Ho, 2009), which has led to the situation that almost $100 \%$ of the secondary school graduates enter higher educational system in 2003. Since then, the higher educational institutions produce several times as many college graduates each year as there are jobs available in Taiwan. This coupled with the deep recession of economy in recent years have contributed to the intensified competition for jobs. Higher education graduates can hardly find adequate employment upon graduation, and many graduates are placed in jobs not comparable to their qualification, still many are lacking security of their working life (Yang, Chen, and Fan, 2010). This fierce unemployment among young people has revived the demand on the contribution of educational system to the employability of college graduates (Cassidy and Wright, 2008; Perez, Garrouste, and Kozovska, 2010; Núñez and Livanos, 2010).

University undergraduates, though have not yet experienced the real world of employment, are aware of the challenges facing them, and therefore, undergraduate years are the crucial stage when students begin to construct their working competence and their career prospects (Al-Harthi, 2011). The shift from higher education to employment is a major but difficult transition of young adults' life. Most college students felt uncertain about their future and were not confident that the knowledge and skills acquired in schools would lead to a successful transition (Rothwell, Herbert, and Rothwell, 2008; Lairio and Penttinen, 2006).

Hence, career guide or career preparation has become a major task of college and universities. Students having career preparation experiences not only possess better employable knowledge and skills, but they also have higher self-awareness and better understanding of occupations (Sagen, Dallam, and Laverty, 2000). Since exploring how students define an ideal job is a prerequisite for guiding them to get a job that better matches their skills and desires, this research is thus endeavored to probe into the questions of: 
1) What are the major determinants of career selection perceived by students?

2) What is the relative importance of each determinant?

3) What are the major strengths of different jobs?

4) What are the ideal jobs perceived by students?

\section{Literature Review}

In this section, we review the critical points of current knowledge and substantive findings on employability in higher education. We first discuss the university's responsibility in enhancing graduate employability, and then identify the determinants of students' career selection, and finally, students' competence for employability is deliberated.

\subsection{Enhancing Graduate Employability}

Employability is defined as having the skills and abilities to find employment, remain in employment or obtain new employment (Crossman and Clarke, 2010). Since employability highly correlates with good learning, it has long being a major task for universities to ensure students learn much from their school studying (Dedmond, 1996; Goh and Lee, 2003; Yorke and Knight, 2006). Moreover, universities are not only demanded to provide students quality education and training, they are also expected for promoting the conditions in which they can be put to use (Al-Harthi, 2011). As more university graduates face the prospects of unemployment and underemployment, higher educational institutions are currently facing significant challenges to enhance the employability of their graduates (Menon, et al., 2012).

Cranmer (2006) argues that universities should redirect a certain proportion of their resources from classroom-based learning to employment-based training, and invite employers to involve in courses, which were found to positively affect immediate graduate prospects in the labor market. Universities should also explore in depth factors relevant to job selection. This information will be used to provide insights about the design and operation of the career planning program offered by universities, and to improve and refine students' career planning process.

\subsection{Determinants of Students' Employment Selection}

Both institutional and individual factors influence graduates' career success, and therefore, although most of the research on graduate employability put focus on institutional supports, individual efforts play an even more important role in graduates' career success. This paragraph is thus devoted to individual efforts in enhancing employability, with a special focus on determinants of students' employment selection.

Most undergraduate students report experiencing some amount of career related anxieties or indecision. This kind of negative emotion could affect students' commitment to their school work, and if the anxiety remains unresolved, students may be less committed to their career and experience less career satisfaction (Daniels, et al., 2011). Moynihan, et al. (2003) also asserts that students who are more aware of their job searching skills and process were more efficient in converting interviews into job offers. In order to help students make career decisions and relieve their career related anxieties, it is crucial to know how they define an ideal job.

Block, Denker, and Tittle (1981) identify six categories of factors that have influences on career choices, and they are Ability: talents, capacities, or personality characteristics; Interest: preference for a particular of work; Goal-Directed: accomplishment, achievement, or satisfaction at attaining a personal goal; Practical Consideration: job availability, educational prerequisites, and security; Prestige: rising in the hierarchy; and Financial Aspects: pays well. Liu, Thomas, and Zhang (2010) suggest that there are seven elements relevant to an ideal job: pay, fringe benefits, work challenges, promotion opportunity, opportunity of use education, job security, and opportunity for further education. Mau and Kopischke (2001) hold similar opinions with Liu, Thomas, and Zhang, and they define Job satisfaction by nine factors: pay, employment benefit, work challenges, working conditions, opportunities for promotion, job security, supervisor, coworkers, and educational benefits.

Harpaz (1990) investigated the differences of "ideal jobs" among different countries. She examined the question of what individuals seek from working, and she found that the two most dominant elements were "interesting work" and "good pay", and these two answers were consistent among the 7 European countries she examined. Several years later, Harzing (2004) constructed another research to identify the major factors making an ideal job, and she found that, in general, the three most important factor contributing to an ideal job were money (have an opportunity for high earning), prestige (work in a prestigious, successful company or organization) and advancement (have an opportunity for advancement to higher level jobs). 


\subsection{Competence Required for Employment}

As with career selection, it is likely that negative attitudes toward some competences affect career decisions (Welborn and McKenzie, 1989). In other words, lack of competence or interests could be an important determinant for job selection. This paragraph is thus dedicated to discussing competences required for employment.

Sanyal (1982) claims that there are sixteen factors in three domains that together form the competence of a worker: the cognitive domain consists knowledge, comprehensive, application of general ideals or methods to new situation, analysis, synthesis, and evaluation; the affective domain include receiving or attending, responding, valuing, organization of the values into a system, characterization by a value or value complex; and finally the psycho-motor domain deals with imitation, manipulation, precision, articulation, and naturalization.

Husain, et al. (2010) suggest that there are seven employability skills identified by employers, and the most important skills are personal quality, followed by interpersonal skills, resources skills, basic skills, information skills, thinking skills and system and technology skills. Ramli, Nawawi, and Chun (2010) also investigated the employers' perceptions of employability skills, and they classified the employability skills into nine categories: problem solving, decision making, organization and time management, communication, interpersonal skills, leadership, lifelong learning, professional behavior (such as honest and know his own limitations) and personal strength (such as responding positively to criticism and ability to work independently).

Al-Harthi (2011) claims that current working environments require graduates to be more flexible to keep up with the continuous changes in this knowledge-based era, and therefore, generic knowledge is highly required. Crossman and Clarke (2010) agree with Al-Harthi's opinions, and they claim that other than critical subject specific knowledge and skills, students should also possess transferable skills for employment. Transferable skills include oral communication, high level learning, problem solving, decision making and affective skills. Moreover, personal trait such as responsibility, positive attitude, interpersonal skills and ability and willingness to work both in a team and independently are also required for employability.

One of the constraints of building a more uniformed employability for university graduates is the diversity of employment. Different employment needs different key skills. However, despite the different skills required, graduates tend to select a job requiring skills they can afford (Hills, Robertson, Walker, Adey, and Nixon, 2003). Career self-efficacy - encompassing judgments of personal competence in relation to the activities involved in career choice and adjustment is a crucial factor contributed to job selection (Mathieu, Sowa, and Niles, 1993).

\section{Methodology}

The purpose of this section is to describe the research design and methods adopted in this study. We first explain the reason for adopting AHP as the major research method. Thereafter, we portray the merits of correspondence analysis, and finally, a general description of the participants and sampling methods is illustrated.

\subsection{The Analytic Hierarchy Process}

The Analytic Hierarchy Process (AHP) was adopted in this research as the main instrument for measuring the relative importance of each determinant of graduates' job selection. AHP is applied in breaking down a big unstructured problem into several smaller parts. These smaller parts are more easily solved, and are arranged in a hierarchy that elucidates the subordinate relationships between each of the factors being examined. The primary goal occupied the highest level. The second level consists of all the secondary goals that together contribute to accomplishing the primary goal. In turn, each secondary goal is fabricated by the attributes on the next lower level, and so forth. The AHP helps to elicit opinions from experts, generates weights to each element, validates the consistency of the ratings, and helps decision makers to select the best answer from many complex alternatives (Saaty, 1990). We selected AHP as the main research tool for this study because it is the best method for calculating the relative importance of the determinants being examined. Thereafter, an AHP questionnaire was developed, and the relative weights of the attributes are obtained by comparing them in pairs of verbal judgments. A positive reciprocal matrix is then utilized to calculate the relative weights of each attribute. Thereafter, an eigenvector $\lambda_{\max }$ is used to assess the consistency of the structure.

We developed the AHP structure based on the literature reviewed above. In Figure 1, the main goal, located at the topmost level (on the far left), is to select the best job; the second level consists of the three major dimensions: Workload and Benefits, Future Prosperity, and Self-Actualization; and the third level consists of the eight determinants of students' career selection: Good Pay, Abundant Fringe Benefits, Adequate Workload, Opportunities for Promotion, Reliable Job Security, Appropriate Retirement Policy and Benefits, Good Chance for Self-Development, and High Prestige. 


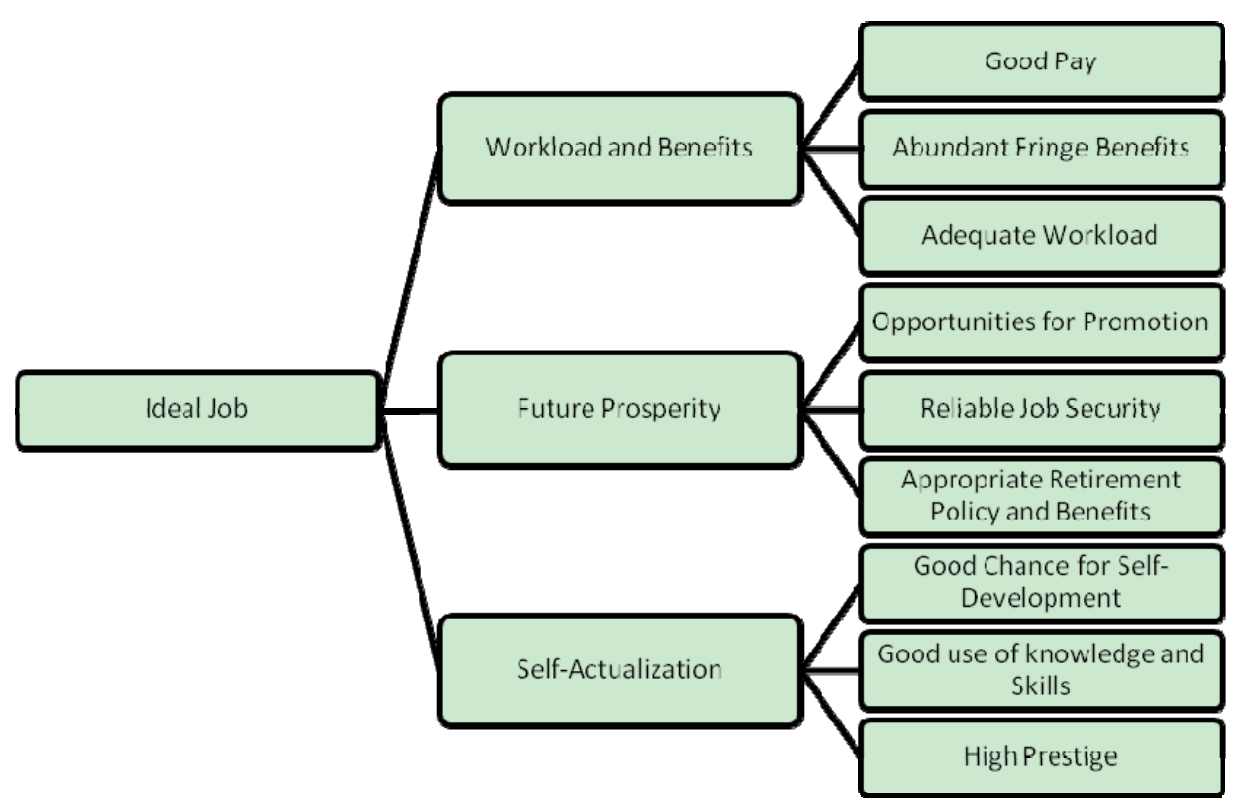

Figure 1.

\subsection{Correspondence Analysis}

Correspondence analysis (CA) is a multivariate statistical technique to visualizing categorical data. CA technique transforms a table of nominal variables into a two-dimensional graphic, in which the heading of each roll and each column is shown as a point. The use of correspondence analysis and perceptual mapping techniques can best be used to identify patterns of results and can reveal possible options for policy decisions (Greenacre and Blasius, 1994; Allen, Thom, and Buckner, 2010). A chi-square statistic is then applied to measure the distance between points on the perceptual map, and a p-value smaller than 0.05 indicates that the hypothesis of the study is plausible (Habib, Etsam Ghoddusifar, and Mohajeri, 2012). To perform the correspondence analysis in this research, we created a cross-table with eight row variables (the determinants of job selection) and eleven column variables (different jobs).

\subsection{Design of the Questionnaire}

A self-developed questionnaire was developed to measure the relative importance of job selection determinants. The questionnaire consisted three parts. The first part consisted of questions about the participant's demographical information; the second part consisted of 12 pairs of questions for AHP analysis; the third part was a cross table with the rows consisted of eleven jobs and the column consisted of nine job selection determinants.

\subsection{Research Participants}

College students were targeted as the research participants for this study. The sampling method employed was mainly purposive. As suggested by Tudd, Smith and Kidder (1991), probability sampling may be more representative, but the advantages of non-probability sampling may outweigh those of probability sampling due to practical constrains. Hence, purposive sampling was adopted in this study because of the expected low retrieve rate and the similarity of student bodies among universities in Taiwan. The questionnaire was administered to 150 college students at National Chiayi University. A total of 130 questionnaires were returned and valid for the forthcoming AHP and correspondence analysis.

\section{Research Results}

\subsection{Participants' Demographic Characteristics}

The sample consisted of 130 students with 32 (25\%) male and 98 (75\%) female students. 38(29\%) participants were freshmen, 27 (21\%) were sophomore, 38(29\%) were junior, and 27 (21\%) were senior. 19 (15\%) students came from financially more disadvantaged families, 100 (77\%) from moderate prosperity families, and 11 (8\%) from richer families. 


\subsection{Results of AHP}

Microsoft Excel was adopted for conducting the AHP procedure. The second- and third-level AHP procedures all contained more than two alternatives, and therefore, eigenvector consistency tests were applied to confirm the reliability and validity. The CR value of the positive matrix at the second level was 0.002 , and the $\mathrm{CR}$ value of the three positive matrixes at the third level were $0.000,0.001$, and 0.000 , all far below the 0.1 standard suggested by Saaty (1990), thus confirming their reliability and validity.

Microsoft Excel was then adopted again for calculating the weight of the dimensions (located at the second level), and the determinant of job selection (the third level). The result of the AHP analysis (Table 1) showed that the most important dimension of job selection perceived by students was Future Prosperity (.426),followed by Self-Actualization (.355), Workload and Benefits (.219).

Table 1. Weights of the two dimensions

\begin{tabular}{lllll}
\hline Major Goal & CR & Dimension & Weight & Order \\
\hline \multirow{3}{*}{ Ideal Job } & \multirow{2}{*}{.002} & Workload and Benefits & .219 & $(3)$ \\
& & Future Prosperity & .426 & $(1)$ \\
& & Self-Actualization & .355 & $(2)$ \\
\hline
\end{tabular}

The results for the third level of the AHP analysis (Table 2) showed that Reliable Career Security (.207) was considered to be the most important factor. This was followed by, in descending order, Appropriate Retirement Policy and Benefits (.152); Good Use of Knowledge and Skills (.130); High Prestige (.116); Good Chance of Self-Development (.110); Abundant Fringe Benefits (.102); Opportunities for Promotion (.082); and Adequate Workload (.035).

Table 2. Weights of the eight determinant factors

\begin{tabular}{|c|c|c|c|c|c|}
\hline $\begin{array}{l}\text { Major } \\
\text { Goal }\end{array}$ & Dim. & $\mathbf{C R}$ & Determinant Factor & Weight & Order \\
\hline \multirow{9}{*}{ Ideal Job } & \multirow{3}{*}{$\begin{array}{l}\text { Workload } \\
\text { and Benefits }\end{array}$} & \multirow{3}{*}{.003} & Good Pay & .082 & (8) \\
\hline & & & Abundant Fringe Benefits & .102 & (6) \\
\hline & & & Adequate Workload & .035 & (9) \\
\hline & \multirow{3}{*}{$\begin{array}{l}\text { Future } \\
\text { Prosperity }\end{array}$} & \multirow{3}{*}{.005} & Opportunities for Promotion & .067 & (7) \\
\hline & & & Reliable Job Security & .207 & (1) \\
\hline & & & Appropriate Retirement Policy and Benefit & .152 & (2) \\
\hline & \multirow{3}{*}{$\begin{array}{l}\text { Self- } \\
\text { Actualization }\end{array}$} & & Good Chance for Self-Development & .110 & $(5)$ \\
\hline & & & Good Use of Knowledge and Skills & .130 & (3) \\
\hline & & & High Prestige & .116 & (4) \\
\hline
\end{tabular}

\subsection{Result of Correspondence Analysis}

The final step was to use CA to produce a perceptual map which displays the level of benefits of each of the careers. The $\mathrm{X}^{2}$ of 1637.486 and the $\mathrm{CR}$ value of .000 indicated that the perceptual map created by CA was feasible.

In the perceptual map (Figure 2) it can be seen that the benefits and careers roughly form into four groups. The map shows that Public School Teacher and Government Officer and Military and Policemen have the most bearing on Job Security, Fringe Benefits and Retirement Policy; Business Manager have the most bearing on Use of Knowledge and Self-Development; Self-Run Business and Private School Teacher have the most bearing on Good Pay; Non-Benefit Institution and Business Staff have the most bearing on Promotion. Understanding that different careers have different benefits can help students to select in a timely manner the most appropriate career. 


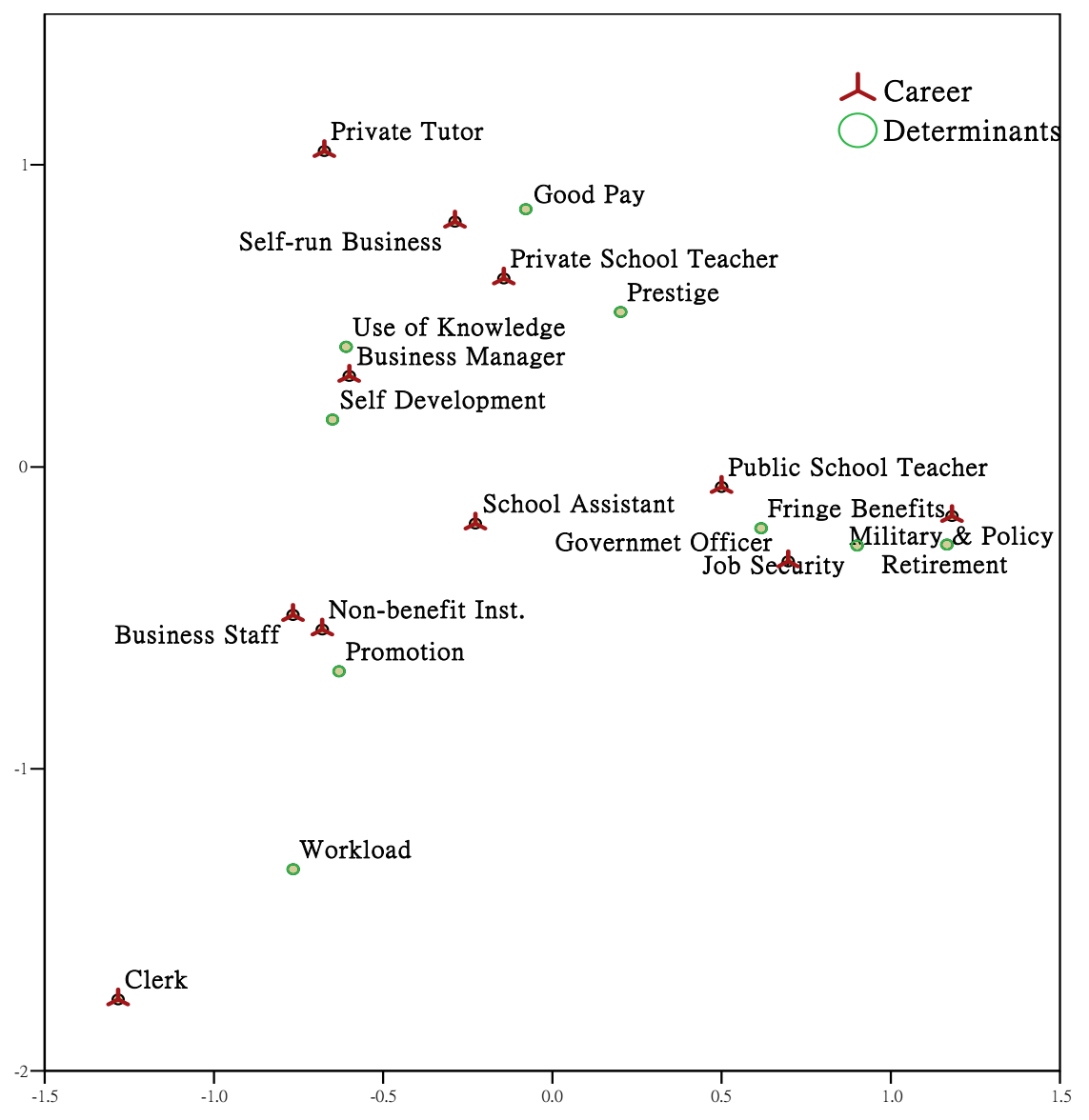

Figure 2.

\section{Conclusion and Implications}

Since exploring how students define an ideal job is a prerequisite for guiding them get a job that better matches their skills and desires, this research is endeavored to identify the major determinants of career selection perceived by students, to calculate the relative importance of each determinant, and to decide the major strengths of different careers.

The results for the third level of the AHP analysis (Table 2) showed that Reliable Career Security was considered to be the most important factor. This was followed by, in descending order, Appropriate Retirement Policy and Benefits; Good Use of Knowledge and Skills; High Prestige; Good Chance of Self-Development; Abundant Fringe Benefits; Opportunities for Promotion; and Adequate Workload. It is worth notice that most scholars assert that students emphasize mostly on the good pay when deciding their career track, however, the result of this research showed that students stress more on career security and retirement policy in Taiwan rather than good pay. The possible reason for this phenomenon is that the recent economic stagnate in Taiwan has increased the difficulty of finding a job, and therefore, job security has become the most important determinant for career selection.

Understanding that different careers have different benefits can help students to select in a timely manner the most appropriate career. The result of the correspondence analysis showed that the benefits and careers roughly form into four groups. Public School Teacher and Government Officer and Military and Policemen have the most bearing on Job Security, Fringe Benefits and Retirement Policy; Business Manager have the most bearing on Use of Knowledge and Self-Development; Self-Run Business and Private School Teacher have the most bearing on Good Pay; Non-Benefit Institution and Business Staff have the most bearing on Promotion. Given the aforementioned results, it is obvious that the careers in the public sector (public school teacher, government officer, and military or policemen) are strongly related with the benefits most stressed by students- Career Security and Retirement Policy, which indicates they are the jobs most preferred by students major in education. 
Unfortunately, although public sector careers are very welcome by students, only a tiny proportion of college graduates end up working in jobs in public sector. This miserable reality may be attributed to the severe shortages of public sector careers in Taiwan, which have forced students to spend years and a significant amount of money preparing for the entrance examination of public sector careers, but the results are often dismal. For those who failed many times in passing the public sector career exams, they were forced to take careers in other sectors reluctantly, which in turn decreases their job engagement and satisfaction. Therefore, universities should strengthen their career counseling services to relieve students' career anxiety and enhance students' career adaptability.

\section{References}

Al-Harthi, H. K. (2011). University student perceptions of the relationship between university education and the labour market in Egypt and Oman. Prospects, 41, 535-551. http://dx.doi.org/10.1007/s11125-011-9216-4

Baron, C., \& Ortiz, L. (2011). Overeducation among European university graduates: A comparative analysis of its incidence and the importance of higher education differentiation. Higher Education, 61, 325-337. http://dx.doi.org/10.1007/s10734-010-9380-0

Block, J., Denker, E. R., \& Tittle, C. K. (1981). Perceived influences on career choices of eleventh graders: Sex, SES, and ethic group comparisons. Sex Roles, 7(9), 895-904. http://dx.doi.org/10.1007/BF00290973

Cassidy, T., \& Wright, L. (2008). Graduate employment status and health: A longitudinal analysis of the transition from student. Social Psychology of Education, 11(2), http://dx.doi.org/10.1007/s11218-007-9043-x

Cranmer, S. (2006). Enhancing graduate employability: Best intentions and mixed outcomes. Studies in Higher Education, 31(2), 169-184. http://dx.doi.org/10.1080/0375070600572041

Crossman, J. E., \& Clarke, M. (2010). International experience and graduate employability: Stakeholder perceptions on the connection. Higher Education, 59, 599-613. http://dx.doi.org/10.1007/s10734-009-9268-z

Daniels, L. M., Stewart, T. L., Stupnisky, R. H., Perry, R. P., \& Verso, T. L. (2011). Relieving career anxiety and indecision: The role of undergraduate students' perceived control and faculty affiliations. Social Psychology of Education, 14(3), 409-426. http://dx.doi.org/10.1007/s11218-010-9151-x

Dedmond, R. M. (1996). Evaluation of the career planning program. Journal of Career Development, 23(1), 83-93.

Goh, M., \& Lee, J. (2003). Career counseling centers in higher education: A study of cross cultural applications from the United States to Korea. Asia Pacific Education Review, 4(1), 84-96.

Harpaz, I. (1990). The importance of work goals: An international perspective. Journal of International Business Studies, 21, 75-93. http://dx.doi.org/10.1057/palgrave.jibs.8490328

Harzing, A. (2004). Ideal jobs and international student mobility in the enlarged European Union. European Management Journal, 22(6), 693-703. http://dx.doi.org/10.1016/j.emj.2004.09.032

Hills, J. M., Robertson, G., Walker, R., Adey, M. A., \& Nixon, I. (2003). Bridging the gap between degree programme curricula and employability through implementation of work-related learning. Teaching in Higher Education, 8(2), 211-231. http://dx.doi.org/10.1080/1356251032000052456

Ho, H. F. (2009). From lofty ideals to painful failures: Lessons from the rapid expansion of higher education in Taiwan. US-China Education Review, 6(9), 9-15.

Husain, M. Y., Mokhtar, S. B., Ahmad, A. A., \& Mustapha, R. (2010). Importance of employability skills from employers' perspective. Procedia Social and Behavioral Sciences, 7(c), 430-438. http://dx.doi.org/10.1016/j.sbspro.2010.10.059

Lairio, M., \& Penttinen, L. (2006). Students' career concerns: Challenges facing guidance providers in higher education. International Journal of Educational and Vocational Guidance, 6(3), 143-157. http://dx.doi.org/10.1007/s10775-006-9107-z

Liu, X., Thomas, S., \& Zhang, L. (2010). College quality, earnings, and job satisfaction: Evidence from recent college graduates. Journal of Labor Research, 31(2), 183-201. http://dx.doi.org/10.1007/s12122-010-9086-1 
Mathieu, P. S., Sowa, C. J., \& Niles, S. G. (1993). Differences in career self-efficacy among women. Journal of Career Development, 19(3), 187-196. http://dx.doi.org/10.1007/BF01353277

Mau, W., \& Kopischke, A. (2001). Job search methods, job search outcomes, and job satisfaction of college graduates: A comparison of race and sex. Journal of employment counseling, 38, 141-149.

Menon, M. E., Pashourtidou, N., Polycarpou, A., \& Pashardes, P. (2012). Students' expectations about earnings and employment and the experience of recent university graduates: Evidence from Cyprus. International Journal of Educational Development, 32, 805-813. http://dx.doi.org/10.1016/j.ijedudev.2011.11.011

Moynihan, L. M., Roehling, M. V., LePine, M. A., \& Bosewell, W. R. (2003). A longitudinal study of the relationships among job serch self-efficacy, job interviews, and employment outcomes. Journal of Business and Psychology, 18(2), 207-233.

Núñez, I., \& Livanos, I. (2010). Higher education and unemployment in Europe: An analysis of the academic subject and national effects. Higher Education, 59, 475-487. http://dx.doi.org/10.1007/s10734-009-9260-7

Perez, E. A., Garrouste, C., \& Kozovska, K. (2010). Employability: Challenges for education and training systems. In M. D. Lytras, et al. (Eds.), Technology Enhanced Learning: Quality of teaching and educational reform, 73, 292-300. http://dx.doi.org/10.1007/978-3-642-13166-0_42

Ramli, A., Nawawi, R., \& Chun, M. P. P. (2010). Employees' perception of employability skills needed in todays' workforce among physiotherapy graduates. Procedia Social and Behavioral Sciences, 7(c), 455-463. http://dx.doi.org/10.1016/j.sbspro.2010.10.062

Rothwll, A., Herbert, I., \& Rothwell, F. (2008). Self-perceived employability: Construction and initial validation of a scale for university students. Journal of Vocational Behavior, 73, 1-12. http://dx.doi.org/10.1016/j.jvb.2007.12.001

Saaty, T. L. (1990). Decision making for leaders: The analytic hierarchy process for decisions in a complex world. Pittsburgh, PA: RWS Publications.

Sagen, H. B., Dallam, J. W., \& Laverty, J. R. (2000). Effects of career preparation experiences on the initial employment success of college graduates. Research in Higher Education, 41(6), 753-767.

Sanyal, B. C. (1982). Alternative structures of higher education and the world of work. International Review of Education, 28(2), 239-257. http://dx.doi.org/10.1007/BF00598449

Teichler, U. (1999). Research on the relationships between higher education and the world of work: Past achievements, problems and new challenges. Higher Education, 38(2), 169-190. http://dx.doi.org/10.1023/A:1003761214250

Welborn, T., \& McKenzie, D. L. (1989). Science achievement, attitudes and career selection of females: A review of research. Journal of Elementary Science Education, 1(2), 3-9.

Yorke, M., \& Knight, P. (2006). Curricula for economic and social gain. Higher Education, 51(4), 565-588. http://dx.doi.org/10.1007/s10734-004-1704-5 